\title{
ABCD Survey: Life as a diabetologist during the COVID-19 pandemic
}

\author{
SUSANNAH ROWLES, ${ }^{1}$ DIPESH PATEL, ${ }^{2}$ ANDREW MACKLIN,${ }^{3}$ UMESH DASHORA ${ }^{4}$
}

\section{Introduction}

It was General Norman Schwarzkopf, who was quoted as saying: "It doesn't take a hero to order men into battle. It takes a hero to be one of those men who goes into battle."

Diabetologists are up for anything, even the fight against COVID-19. In just over three weeks between 2 and 23 April 2020, 26,566 people died in the UK from this novel virus, more than half the total worldwide reported toll of 52,161 deaths to 5 June 2020, elevating the status of the UK to that of the worst affected country in Europe at that time.

We are now surfing the second wave of the pandemic which is compounded by seasonal complexities of influenza and an increasingly indoor life style. Current figures (November 2020) show a worldwide death rate of 1.43 million with 56,533 deaths in the UK.

$A B C D$ is a registered charity whose membership consists in the main of practising diabetologists and specialty trainees, including those based in district general hospitals, academic institutions and community settings. The $A B C D$ executive deemed that a snapshot survey collected at the height of the first wave of the pandemic would provide invaluable information from which to learn.

Acknowledging the time constraints placed upon our membership at this time, the survey was designed to be brief and succinct while still offering the opportunity for free text feedback. The submission window was purposely narrow to allow rapid assimilation of the data and early learning to be shared

\section{Method}

Three areas of focus were identified by the ABCD executive team (Chairs (outgoing Dinesh Nagi, incoming Dipesh Patel)), Treasurer (Andrew Macklin), Meetings Secretary (Umesh Dashora) and Secretary (Susannah Rowles) during weekly scheduled video conference calls.

Twelve questions were asked in total: four pertaining to the

Pennine Acute Hospitals NHS Trust, UK

2 Royal Free Hospital, London, UK

3 Dorset County Hospital, Dorchester, UK

4 Conquest Hospital, Hastings, East Sussex, UK

Address for correspondence: Dr Susannah Rowles

Pennine Acute Hospitals NHS Trust, Fairfield Hospital, Rochdale Old Rd, Bury BL9 7TD, UK

E-mail: secretary@abcd.care

https://doi.org/10.15277/bjd.2020.269

Br J Diabetes 2020;20:163-165 deployment of the workforce, three questions addressing clinical pathological presentation of COVID-19 in people with diabetes and four questions tackling the well-being of our members and their teams. The final question was a free text feedback box.

$A B C D$ 's secretariat, Red Hot Irons Ltd, prepared the survey directly within the membership database (CiviCRM) and an email with a link to the survey was sent to the membership. The survey was open for completion from Monday 27 April to Saturday 9 May 2020. Each member was sent three reminders to participate as well as the initial invitation.

\section{Results}

At time of the survey, ABCD had a UK membership of 510. A total of 188 responses were received ( 172 consultant physicians, 13 specialty trainees, 3 'other'), 172 from members $(92.8 \%)$ and 16 from non-members. This response rate reflects 33.9\% of membership.

\section{Work force}

What proportion of local D\&E consultants are doing additional acute medical rota duties?

$\begin{array}{ll}<25 \% & 16 \\ 26-50 \% & 23 \\ 51-75 \% & 45 \\ >76 \% & 104\end{array}$

Do you have to work full night shifts?

$\begin{array}{ll}\text { Yes } & 53 \\ \text { No } & 135\end{array}$

What proportion of your departmental colleagues have been or are self-isolating?

$\begin{array}{ll}<25 \% & 97 \\ 26-50 \% & 69 \\ 51-75 \% & 17 \\ >76 \% & 5\end{array}$

Have youlyour teams been mandated to de-escalate speciality activity or have you managed this yourself?

$\begin{array}{ll}\text { De-escalate speciality activity } & 122 \\ \text { Managed yourself/ourselves } & 66\end{array}$




\section{Pathology}

Have you had direct experience of an increase in new diabetes diagnoses (of all types of diabetes) precipitated by COVID-19 infection?

$\begin{array}{ll}\text { Yes } & 44 \\ \text { No } & 144\end{array}$

Have you had any atypical presentations of diabetic ketoacidosis (DKA) since the start of the pandemic?

Yes 103

No $\quad 85$

Did this involve sodium-glucose co-transporter-2 (SGLT-2) inhibitors?

Yes $\quad 39$

No 63

Has your Trust had COVID-19 positive patients (mainly in critical care) with significant insulin resistance (insulin infusion rate of $>2$ units/kg/day or $>10$ units/hour)?

$\begin{array}{ll}\text { Yes } & 83 \\ \text { No } & 105\end{array}$

\section{Well-being}

Has your trainees' exposure to speciality training changed?

$\begin{array}{ll}\text { Yes } & 177 \\ \text { No } & 3 \\ \text { Don't know } & 8\end{array}$

Do you think there are adequate training opportunities for your juniors at present?

$\begin{array}{ll}\text { Yes } & 48 \\ \text { No } & 121 \\ \text { Don't know } & 19\end{array}$

Do you and your colleagues feel adequately supported by your organisation?

$\begin{array}{ll}\text { Yes } & 153 \\ \text { No } & 35\end{array}$

Have you found the ABCD COVID-19 web pages useful?

$\begin{array}{ll}\text { Yes } & 130 \\ \text { No } & 3\end{array}$

I've not looked 55

Is there anything you feel $A B C D$ could be doing to helplanything else you'd like to share?

\section{Thematic analysis of free text responses}

\section{Work force (69 comments)}

Preservation of acute foot and antenatal services. Rapid move to virtual phone or video calls. Night shifts planned but not needed. Only one mention of concerns re Personal Protective Equipment (PPE).

\section{Pathology (39 comments)}

Mixed pictures of diabetic ketoacidosis (DKA) and hyperosmolar hyperglycaemic state (HHS) seen together. Mention of confounders of hyperglycaemia: dexamethasone in recovery trial, nasogastric feeding and inotropes in ICU setting

\section{General feedback (37 comments)}

Positive comments concerning $A B C D$ website and guidance. Need to focus on a recovery plan.

\section{Discussion}

A response rate of $34 \%$ of our membership for an email/online survey is above average. Taking into account the extraordinary circumstances that the NHS were addressing, it appears that diabetologists are keen to engage in sharing experience and contributing to rapid learning from each other.

It is an ongoing bone of contention and a deterrent to trainees choosing higher medical training that our membership has a disproportionally high contribution to the acute medical on-call rota; $55 \%$ of respondents had more than three-quarters of their consultant colleagues undertaking acute medical rota duties.

At the time of the survey there was still some ambiguity around criteria for shielding, and anosmia had not been added to the COVID-19 defining clinical symptoms; $51 \%$ of units had only a minority of colleagues self-isolating. Further detail was ascertained via free text. Colleagues had come out of retirement in three units and the majority of units had pragmatically divvied up their expertise taking into account individual health needs and skill set. Antenatal and acute foot services were preserved; however, the format was changed wherever possible to minimise face-to-face contact.

Although there was no reported increase in new diagnoses of diabetes precipitated by COVID-19, this could be for a number of reasons: patient contact with Primary Care was severely curtailed at this time, as was access to phlebotomy services. It can be postulated that there may be a future surge in cases of type 1 diabetes, as is seen seasonally in spring and autumn and has historically been linked with a higher viral load; however, this is likely to be delayed in clinical onset. There is also emerging data around a non-autoimmune insulin-requiring form of diabetes.

Possibly the most interesting response, raising the most questions and highlighting areas for further study, is the high rate of atypical presentations of DKA (55\%) and the involvement of SGLT2 inhibitors in $21 \%$ of those. We do not know what proportion of these patients, who presumably sustained an acute beta cell injury, will require insulin in months and years to come. $A B C D$ has produced some useful guidance for healthcare professionals and people with diabetes who take SGLT-2 inhibitors. ${ }^{1}$ 
Early reports of severe insulin resistance from the London area in patients with COVID-19 prompted us to ask about significant insulin resistance as defined by the need for an insulin infusion rate of $>2$ units $/ \mathrm{kg} /$ day or $>10$ units/hour. From analysis of the free text, the results may have been skewed by the fact that often the respondent was the member of the unit running the outpatient side of the service. Although many were involved directly with the acute management of COVID-19 patients, this was often not in the HDU/ICU environment. A minority of respondents made reference to a mixed picture of DKA and HHS.

It was heartening to hear that $81 \%$ of the respondents felt adequately supported by their organisation. Three free text references were made to additional stress caused by poor access to PPE; however, in the period from 27 April to 9 May information was changing on a daily basis as to the need for varying levels of PPE and risk stratification of the workforce.

The fact that our trainees' speciality training has been compromised will come as no surprise; $64 \%$ felt that their juniors did not have adequate training opportunities. Having robust data as opposed to anecdote may help support Training Programme Directors and Speciality Advisory Committee Chairs in drawing up plans for trainees in future waves of the pandemic.

Feedback was overwhelmingly positive about the usefulness of the ABCD COVID-19 web pages; this was encouraging for all those who contributed to the guidance, often with tight deadlines, and simultaneously managing their own local clinical service pressures or whilst recovering from the virus themselves

\section{Direct outcomes from the survey}

$A B C D$ was keen to utilize any learning from the survey analysis in a timely fashion. Data pertaining to the higher rate of atypical presentation of DKA with or with or without SGLT 2 involvement was shared with the ABCD committee on July 1st 2020 and sub- sequently shared in webinars. Sick day rules and drugs to "pause" when unwell, were reiterated and there is now a downloadable leaflet available on the ABCD website.

Consideration is now being given to the potential for a second survey focusing on the recovery/re-booting of services as well as planning for future waves of the virus during the predictable winter pressures of seasonal influenza and cold weather, and to ascertain if there has been an increase in newly diagnosed type 1 diabetes ${ }^{2,3}$ and to glean information on the emergence of a novel non-autoimmune insulin-requiring ketosis-prone diabetes that may be transient or permanent. The ABCD COVID-19 audit will also offer vital information (http://www.diabetologists-abcd.org.uk/Coronavirus/ COVID-19_Diabetes_Nationwide_Audit.htm). With increased understanding of the role and use of therapies such as dexamethasone, there are likely to be further knock-on consequences for people with diabetes and newly diagnosed steroid-induced diabetes.

\section{Conflict of interest None. Funding None.}

\section{References}

1. Dashora U, Patel DC, Gregory R, Winocour P, Dhatariya K, Nagi D. Association of British Clinical Diabetologists ( $A B C D$ ) position statement on the use of sodium-glucose cotransporter-2 inhibitors in type 1 diabetes (updated 2019). Br J Diabetes 2019;19.

https://doi.org/10.15277//bjd.2019.208 https://bjd-abcd.com/index.php/bjd/article/view/447

2. Kamrath C, Mönkmöller K, Biester T. Ketoacidosis in children and adolescents with newly diagnosed type 1 diabetes during the COVID-19 pandemic in Germany. JAMA 2020;324:801-04. https://doi.org/10.1001/jama.2020.13445 2 .

https://jamanetwork.com/journals/jama/fullarticle/2768716

3. Rabbone I, Schiaffini R, Cherubini V, et al. Has COVID-19 delayed the diagnosis and worsened the presentation of type 1 diabetes in children? Diabetes Care 2020;43. https://doi.org/10.2337/dc20-1321 3. https://care.diabetesjournals.org/content/early/2020/08/07/dc20-1321 